\title{
Calibration adjustments to address bias in mortality analyses due to informative sampling - a census-linked survey analysis in Switzerland
}

\author{
André Moser ${ }^{\text {Corresp., }}{ }^{1,2}{ }^{\text {, Matthias Bopp }}{ }^{3}$, Marcel Zwahlen ${ }^{2}$ \\ 1 Department of Geriatrics, Inselspital, University Hospital, and University of Bern, Bern, Switzerland \\ 2 Institute of Social and Preventive Medicine, University of Bern, Bern, Switzerland \\ 3 Epidemiology, Biostatistics and Prevention Institute, University of Zürich, Zürich, Switzerland \\ Corresponding Author: André Moser \\ Email address: andre.moser@ispm.unibe.ch
}

Background: Sampling bias, like survey participants' nonresponse, needs to be adequately addressed in the analysis of sampling designs. Often survey weights will be calibrated on specific covariates related to the probability of selection and nonresponse to get representative population estimates. However, such calibrated survey (CS) weights are usually constructed for cross-sectional results, but not for longitudinal analyses. For example, when the outcome of interest is time to death, and sampling selection is related to time to death and censoring, sampling is informative. Then, unweighted or CS weighted inferential statistical analyses may be biased. In 2010, Switzerland changed from a decennial full enumeration census to a yearly registry-based (i.e. data from harmonised community registries) and a survey-based census system. In the present study, we investigated the potential bias due to informative sampling when time to death is the outcome of interest, using data from the new Swiss census system.

Methods: We analysed more than 6.5 million individuals aged 15 years or older from registry-based census data from years 2010 to 2013, linked with mortality records up to end of 2014. Out of this population, a target sample of 3.5\% was sampled from the Swiss Federal Statistical Office (SFSO) in a stratified yearly micro census. The SFSO calculated CS weights to enable representative population estimates from the micro census. We additionally constructed inverse probability (IP) weights, where we used survival information in addition to known sampling covariates. We compared CS and IP weighted mortality rates (MR) and life expectancy (LE) with estimates from the underlying population. Additionally, we performed a simulation study under different sampling and nonresponse scenarios.

Results: We found that individuals who died in 2011 , had a 0.67 [95\% $\mathrm{Cl}(0.64,0.70)]$ times lower odds of participating in the 2010 micro census, using a multivariable logistic regression model with covariates age, gender, nationality, civil status, region and survival information. IP weighted MR were comparable to estimates from the total population, whereas CS weighted MR underestimated the population MR in general. The IP weighted LE estimates at age 30 years for men were 50.9 years $(95 \% \mathrm{Cl}, 50.2$ to 51.6 years), whereas the CS weighted overestimated LE by 2.5 years. Our results from the simulation study confirmed that IP weighted models are comparable to population estimates.

Conclusion: Mortality analyses based on the new Swiss survey-based census system may be biased, because of informative sampling. We conclude that mortality analyses based on census-linked survey data have to be carefully conducted, and if possible, validated by registry information to allow for unbiased interpretation and generalisation. 
1 Calibration adjustments to address bias in mortality analyses due to informative sampling - a census-linked survey analysis in Switzerland

André Moser ${ }^{1,2 *}$, Matthias Bopp ${ }^{3}$, Marcel Zwahlen²

for the Swiss National Cohort study group

(1) Department of Geriatrics, Inselspital, University Hospital, and University of Bern, Bern, Switzerland

(2) Institute of Social and Preventive Medicine, University of Bern, Bern, Switzerland

(3) Epidemiology, Biostatistics and Prevention Institute, University of Zürich, Zürich

\section{Correspondence to:}

Dr André Moser

Institute of Social and Preventive Medicine (ISPM)

University of Bern

Finkenhubelweg 11

$\mathrm{CH}-3012$ Bern, Switzerland

andre.moser@ispm.unibe.ch

Tel +41316315675

Fax +41316313520 
Abstract

Background: Sampling bias, like survey participants' nonresponse, needs to be adequately addressed in the analysis of sampling designs. Often survey weights will be calibrated on specific covariates related to the probability of selection and nonresponse to get representative population estimates. However, such calibrated survey (CS) weights are usually constructed for cross-sectional results, but not for longitudinal analyses. For example, when the outcome of interest is time to death, and sampling selection is related to time to death and censoring, sampling is informative. Then, unweighted or CS weighted inferential statistical analyses may be biased. In 2010, Switzerland changed from a decennial full enumeration census to a yearly registry-based (i.e. data from harmonised community registries) and a survey-based census system. In the present study, we investigated the potential bias due to informative sampling when time to death is the outcome of interest, using data from the new Swiss census system.

Methods: We analysed more than 6.5 million individuals aged 15 years or older from registry-based census data from years 2010 to 2013, linked with mortality records up to end of 2014. Out of this population, a target sample of $3.5 \%$ was sampled from the Swiss Federal Statistical Office (SFSO) in a stratified yearly micro census. The SFSO calculated CS weights to enable representative population estimates from the micro census. We additionally constructed inverse probability (IP) weights, where we used survival information in addition to known sampling covariates. We compared CS and IP weighted mortality rates (MR) and life expectancy (LE) with estimates from the underlying population. Additionally, we performed a simulation study under different sampling and nonresponse scenarios.

Results: We found that individuals who died in 2011 , had a 0.67 [95\% Cl $(0.64,0.70)]$ times lower odds of participating in the 2010 micro census, using a multivariable logistic regression model with covariates age, gender, nationality, civil status, region and survival information. IP weighted MR were comparable to estimates from the total population, whereas CS weighted MR underestimated the population MR in general. The IP weighted LE estimates at age 30 years for men were 50.9 years $(95 \% \mathrm{Cl}, 50.2$ to 51.6 years), whereas the CS weighted overestimated LE by 2.5 years. Our results from the simulation study confirmed that IP weighted models are comparable to population estimates.

Conclusion: Mortality analyses based on the new Swiss survey-based census system may be biased, because of informative sampling. We conclude that mortality analyses based on census-linked survey data have to be carefully conducted, and if possible, validated by registry information to allow for unbiased interpretation and generalisation. 
51 Population based longitudinal studies are a key tool for epidemiologists to investigate individual and ecological risk factors on disease development and mortality over time. In many countries, including the United Kingdom, Germany and the Nordic countries, nationwide cohort studies have been established by linking information from population registries and secondary data sources (Olsen et al., 2001; Ahrens et al., 2014; Connelly \& Platt, 2014). In Switzerland, a nationwide cohort study was established in 2008, based on a probabilistic record linkage of census and mortality information covering the whole Swiss population (Bopp et al., 2009; Spoerri et al., 2010). This cohort study relied on an almost complete census (coverage of $98.6 \%$ (Renaud, 2004)) and allowed for almost unbiased mortality analyses (Schmidlin et al., 2013; Moser et al., 2014).

In 2010, Switzerland changed from a full enumeration census - which was conducted every 10 years - to a registry-based and survey-based census system. This new Swiss census system is based on a yearly updated registry-based census - which collects information from harmonised community registries covering the entire resident population of Switzerland (STATPOP) - and a micro census of roughly $3.5 \%$ of the resident Swiss population aged 15 years or older, living in a private household. This micro census collects individual and household information, which is not available in the STATPOP population (e.g. attained educational level). The new census system aims to be more cost-efficient and to require less administrative resources compared to the traditional full enumeration census. However, because the micro census is based on only a stratified sampled subpopulation, the sampling design needs to be addressed in descriptive and inferential statistical analyses to get valid population estimates (Korn \& Graubard, 1999; Fuller, 2009).

The Swiss Federal Statistical Office (SFSO) planned and performed the sampling of the micro census, and provided calibrated survey (CS) weights for the analysis of the micro census sample. CS weights address the sampling process (i.e. probabilities of selection) and account for sampling biases (e.g. nonresponse adjustments) to get consistent statistical estimates for the whole Swiss population in weighted descriptive analyses (Assoulin, 2012). These analyses are valid for cross-sectional results, but not necessary for longitudinal analyses. For example, if the outcome of interest is time to death and the sampling selection is not independent of the survival time and censoring, given other covariates, the sampling design is called "informative" (Lawless, 2003; Boudreau \& Lawless, 2006). When sampling is informative, the outcome of interest is not missing at random and unweighted or CS weighted inferential 
81 inclusion and censoring, could correct for such bias and lead to valid survival estimates (Scharfstein \&

82 Robins, 2002; Little, 2004; Boudreau \& Lawless, 2006).

83 In the present study, we performed time to death analyses using data from the Swiss micro census. 84 Specifically, we calculated mortality rates (i.e., survival time is an offset variable in a Poisson regression model) and life expectancy (i.e., survival time is directly modelled in a censored skew-normal regression model (Moser, Clough-Gorr \& Zwahlen, 2015)). In Switzerland, non-responders of surveys have a higher risk of dying compared to responders (Bopp, Braun \& Faeh, 2014). Thus, we hypothesised that bias due to informative sampling may exist in CS weighted analyses, caused by unmeasured predictors (e.g. health status), which are possibly related to the sampling process and mortality. We therefore compared CS weighted results with those from an IP weighting approach, which uses known sampling covariates and survival information, and validated our findings using data from the total Swiss population. Additionally, we performed a simulation study to investigate the bias due to informative sampling under different sampling and nonresponse scenarios.

\section{Methods}

\section{Data Availability}

We provide an anonymised dataset of the STATPOP and SE populations of the year 2010 to allow reproducibility of our main results. By law, we are not allowed to provide exact dates (date of birth and date of death). Thus, we rounded necessary main analysis variables (age and follow-up time) to one decimal place. Rounding had no influence on obtained results, compared to results using exact date information. Results in the manuscript are based on exact information. Analysis code for all results is provided in a Supplemental File.

\section{Human ethics}

Federal laws gave the federal authorities the right to collect without consent the census and mortality data used in the SNC. Approval for the anonymous linkage in the SNC was obtained from the Ethics Committees of the Cantons of Zürich (approval no. 13/06) and Bern (approval no. 205/06).

\section{Registry-based population}

We used the STATPOP population of the year 2010 with permanent residents (which excludes crossborder workers) in Switzerland aged 15 years or older. We used information age (5 year categories), gender, civil status (single, married, widowed, other), nationality (Swiss, European Economic Area (EEA), 
110 other Europe, other World), and regional level (cantons of Zurich [subdivided in City of Zurich and 111 remainder], Bern [subdivided in City of Bern, Bernese Jura, and remainder], Lucerne, Uri, Schwyz, 112 Obwalden, Nidwalden, Glarus, Zug, Fribourg, Solothurn, Basel-Stadt, Basel-Landschaft, Schaffhausen, 113 Appenzell Ausserrhoden, Appenzell Innerrhoden, St. Gallen, Graubuenden, Aargau, Thurgau, Ticino, 114 Vaud, Valais, Neuchâtel, Geneva, Jura).

115 Micro census

116 The micro census of the year 2010, subsequently called 'structural enquiry' (SE), is a stratified sample of 117 the permanent residents in Switzerland aged 15 years or older, living in a private household. The 118 sampling aim and planned accuracy of the SE has been described elsewhere (Assoulin, 2012; Qualité, 119 Statistik \& Europe, 2014). In brief, the SE is a regionally-stratified proportional sample with a target sampling fraction of approximately 3.5\%. The regions had the opportunity to increase the sample size to increase precision of statistical estimates, which led to a final sampling fraction of $5.5 \%$ (Rochat, Kauthen

122 \& Eichenberger, 2009). For the SE 2010, the response rate was 87.1\% (Qualité, Statistik \& Europe, 2014). 123 The SFSO calculated individual CS weights based on sampling inclusion and response probabilities 124 (Assoulin, 2012; Qualité, Statistik \& Europe, 2014).

Mortality information

126 Survival status for the years 2011 to 2014 could be one-to-one linked to the STATPOP and the SE 2010 population by unique anonymous personal identifier. The percentage of non-linked death records is $0.2 \%$.

128 Vital status is ascertained by death certificates. We used information about vital status as binary variable 129 (dead: yes or no) and survival time.

Simulation study

We investigated the influence of informative sampling bias in a simulation study. We simulated a population of $1,000,000$ individuals with different sampling and nonresponse scenarios. Our main outcomes were number of deaths and time to death to calculate MR. We performed a simulation study as depicted in Figure 1: We assumed an unobserved predictor (e.g. health status) and observed predictors (e.g. age and gender). On a population level, there is a direct effect of age and gender on health status, e.g. older men are more likely to have a poor health status. Further, health status has a causal effect on survival. Age and gender are related to survival through the unmeasured predictor. A random sample was drawn from the underlying population (planned sampling design). We assumed that

139 a poor health status had a direct effect on the nonresponse, leading to a smaller effective sample. 140 Conditioning on the effective sample opens the path between the random sample and survival (through 
141 nonresponse and the unmeasured confounder) and will lead to a spurious association in survival 142 estimates. We assumed a constant risk of dying over time. For the effect sizes we chose an odds ratio of 4

143 for the association between the unmeasured confounder and nonresponse, and a 4-times higher hazard 144 of dying for individuals with bad health, as reported in Pizzi et al. (Pizzi et al., 2011). We calculated CS 145 weights from varying probabilities of sampling and nonresponse. IP weights were constructed from the 146 probability of 'being sampled' from the total population using vital status. We performed the following 147 simulation scenarios: the overall percentage of deaths was set to $10 \%$ and $25 \%$ for the total population, 148 the sampling fraction was set to $1 \%$ and $10 \%$, and the percentage of nonresponse was set to $10 \%$ and 149 25\%. We ran 1,000 simulation replications. We calculated MR from unweighted Poisson regression 150 models, and models using CS and IP weights, using covariates age and gender. We reported the 1,000 151 replicated mortality rate estimates in scatter plots with bivariate mean location centre estimates and $95 \%$ 152 confidence ellipses from a Gaussian distribution function.

153 Statistical analysis

154 We described the study populations by frequencies (n), percentages (\%), mean and standard deviation 155 (SD). We reported crude odds ratios of participation in the SE 2010 using logistic regression models, for 156 variables age, gender, nationality, civil status and vital status. We calculated MR using Poisson regression 157 models. Remaining LE at age 30 years was calculated from weighted censored skew-normal regression 158 models, accounting for delayed entry (Moser, Clough-Gorr \& Zwahlen, 2015). Because MR and LE were a 159 priori known to differ by gender, we performed analyses for men and women, separately. We calculated 160 IP weights using logistic regression models with an indicator of being a SE 2010 participant in the STATPOP 2010 population. Predictors were chosen according to a priori known covariates for CS weights, 162 i.e. age, gender, nationality, civil status, region (Assoulin, 2012), and additional survival information. We 163 included interactions between age, gender and survival information. Because the main outcome of 164 interest is time to event we included the Nelson-Aalen estimator in the final IP weighting model (White \& 165 Royston, 2009). Observation time started December 31, 2010, and ended on date of death or December 16631,2011 , whichever came first. The end date changed with the investigated time period, the latest was 167 December 31, 2014. We calculated marginal distributions of the total population from CS and IP 168 weighted estimates. All data were analysed with Stata 14.1 (StataCorp LP, College Station, TX) or R version 169 3.3.1 (2016; The R Foundation for Statistical Computing, Vienna, Austria). The Stata code and command 170 for the censored skew-normal approach is available at https://github.com/MoserGitHub/censn. 
172 We investigated whether the hypothesised bias is present in the years 2011 to 2013 . First, we reported 173 crude odds ratios of participation in one of the SE 2011 to 2013, analysing covariates age, gender, 174 nationality, civil status and vital status (for brevity we did not report estimates of the regional covariate). 175 Second, we investigated whether the hypothesised bias of CS weighted analysis is similarly present in the 176 years 2011 to 2013 , by calculating 1-year MR.

\section{Results}

\section{Study population}

Table 1 summarises the baseline characteristics of the STATPOP population and the SE sample of 2010, by survival status. At 31 December 2010, the STATPOP population consisted of 6.7 million individuals. $49 \%$ of the population was male, $51 \%$ female. More than half of the individuals were married (51.6\%) and most of the individuals were Swiss (77.3\%). Until end of 2011, a total of 61,539 persons died. The 2010 SE sample consisted of 317,079 sampled individuals. The marginal distributions of the covariates for the SE sample and the STATPOP population were roughly the same, except for the regional covariate, which is a sampling stratification covariate. CS weights ranged from 3.3 to 75.0 (mean 20.6, SD 9.4), IP weights ranged from 5.8 to 113.4 (mean 21.2, SD 9.7). There were differences in individuals who died until end of 2011 in the SE sample and the STATPOP population. Individuals who died in the STATPOP population were slightly older: Only $50 \%$ of the individuals were 80 years or older, compared to $57 \%$ in the STATPOP. Further, only $30 \%$ of widowed women died in the SE sample, compared to $37.5 \%$ in the STATPOP population. CS weights - for individuals who died until end of 2011 - were smaller (mean 19.4, SD 9.3) compared to IP weights (mean 30.2, SD 17.3). Supplemental Table 1 summarises the marginal distributions of the baseline characteristics for CS and IP weighted estimates. The marginal distributions were comparable between the STATPOP population and the weighted estimates from the SE sample.

Participation in SE 2010

Table 2 summarises crude odds ratios of being 2010 SE participant with the 2010 STATPOP population as underlying population, using covariates age, gender, nationality, civil status, region and vital status. Individuals aged 85 years or more were less likely to be sampled in the SE 2010 [OR $0.91,95 \% \mathrm{Cl}(0.088$, 0.93)], compared to the youngest age group. Foreigners had a lower odds of participating than Swiss nationals [e.g. OR for persons from EEA 0.94, 95\% Cl $(0.93,0.95)$ ]. Individuals who died in 2011 had a 
202 Figure 2 shows the estimated 1-year MR for the STATPOP population and the SE of the year 2010, by age 203 categories and gender. STATPOP MR (red coloured lines) serve as the reference MR, because they contain 204 full population information. IP weighted MR (green coloured lines) were comparable to STATPOP MR, 205 especially for ages 40 years or older. Unweighted (blue coloured lines) MR and CS weighted (purple 206 coloured lines) MR underestimated the STATPOP MR. Figure 3 shows the estimated LE at age 30 years. 207 The male population of the STATPOP had an estimated LE of 50.9 years ( $95 \% \mathrm{Cl}, 50.8$ to 51.0 years). The 208 IP weighted LE estimates for men were 50.9 years ( $95 \% \mathrm{Cl}, 50.2$ to 51.6 years), whereas the CS weighted 209 were 53.4 years ( $95 \% \mathrm{Cl}, 52.7$ to 54.0 years). The results for women were comparable, i.e. CS weighted 210 results overestimated LE, compared to IP weighted results. Supplemental Table 2 describes the 211 distribution of individuals who died in 2011 for the STATPOP and SE population, across months of death. 212 Individuals who died in January and February were underrepresented in the SE, for example, only $4.8 \%$ of 213 SE 2010 participants who died in 2011 did so in January, compared to $9.3 \%$ in the underlying STATPOP 214 population. This pattern was consistent across all surveys 2010 to 2013. Supplemental Figure 1 shows 215 estimated MR for the STATPOP and SE population of 2010, with an increasing follow-up time until end of 216 2011, 2012, 2013 and 2014. We found that MR differences between the CS and IP weighting approaches 217 diminished with increasing follow-up time.

218 Simulation study

219 Supplemental Figure 2 shows the estimated log MR of the simulated population versus the estimated 220 weighted log MR of the simulated sample. The variability of the estimated weighted log MR of the sample was associated with the sampling fraction and the assumed percentage of deceased individuals. Unweighted analyses showed biased MR estimates for all performed scenarios. We found that IP weighted estimates were comparable to known CS weighted analyses, with a slightly higher bias in a

224 scenario with a low sampling fraction and a low percentage of deceased individuals.

\section{Sensitivity analyses}

226 Supplemental Table 3 summarises crude odds ratios of being SE participant of the years 2011 to 2013 , using covariates age, gender, nationality, civil status, and vital status. We found similar participation patterns as in the year 2010. Supplemental Figure 3 shows the 1-year mortality analyses for the STATPOP and SE populations of the years 2010 to 2013, i.e. mortality in 2011-2014. CS weights showed a reduced

230 bias for later sampling years, but still slightly underestimated the underlying population mortality rates. 
232 We hypothesised that time to event analyses using data from the Swiss survey-based census system may 233 biased, because of informative sampling. We investigated whether an IP weighting approach leads to representative statistical estimates in the analysis of the 2010 SE sample, representing approximately $3.5 \%$ of the Swiss population aged 15 years or older at the end of 2010 . The SE is a stratified random sample of the underlying population, but unweighted and CS weighted survival analyses may be biased, because the sampling is informative. We constructed IP weights, which accounted for known sampling covariates and survival information, and compared those to CS weighted MR and LE estimates. We found that CS weighted estimates were biased, whereas IP weighted estimates were comparable to those from the total Swiss population.

Unmeasured predictors, which are related to future survival and the sampling process - but which are not part of the sampling design - could cause bias in the CS weighted analysis: for example, individuals with a poor health status were less likely to respond to the SE questionnaire, but had also a higher risk of dying. Such a situation may be caused by possible survey participants nonresponse, which is related to certain population characteristics (e.g. older people), which - on the other hand - are also related to the regression outcome (see Figure 1). Bias in the regression analysis of survey data and possible strategies to handle this kind of bias have been extensively discussed in the demographical and statistical literature (see e.g. (Pfeffermann, 2010) and the references therein). Pizzi and colleagues compared results from an internet-based cohort study sample and results from the general population and concluded that differences in estimates between the two analysis populations reflect changes in confounding pattern due to the sampling selection process (Pizzi et al., 2012). Such a change of confounding patterns is likely to influence mortality estimates in our present study using the Swiss population. Confounding patterns in our study are likely to be caused by the underrepresentation of certain subpopulations in the micro census sample. For example, we found that individuals who died in 2011 were less likely to having participated in the micro census of 2010. Specifically, we found that individuals who died in the early months of the year were less likely to participate in the micro census. Delayed information adjustments between the process of sending out questionnaires to individuals, and the alignment between mortality and registry information, could introduce specific nonresponse patterns. Further, our observed lower chance of micro census participation of non-Swiss individuals could be explained by a migrant effect

260 (Nielsen \& Knardahl, 2016). In additional analyses, we found that older foreigners tend to have a higher 261 odd of participation in the survey, than younger individuals, which could be partly explained by the health status of these individuals (Nielsen \& Knardahl, 2016). Such a migrant effect is likely to confound our current analysis. 
264 When sampling design variables are related to survival time and censoring, unweighted survival 265 estimates may be biased (Lawless, 2003; Boudreau \& Lawless, 2006). However, IP weighting approaches, 266 addressing the sampling design and the censoring information, have been shown to provide consistent 267 population survival estimates (Scharfstein \& Robins, 2002; Lawless, 2003; Boudreau \& Lawless, 2006; 268 Pyy-Martikainen, 2013). Several countries, also Switzerland, reported a higher risk of death among non269 responders of surveys, compared to responders (Barchielli \& Balzi, 2002; Bopp, Braun \& Faeh, 2014). An 270 Australian study investigated attrition patterns over five survey periods, starting in 1996 to 2008, in a 271 population of older women, and reported that health status was associated with frailty, withdrawal from 272 the study, and lost to follow-up (Brilleman, Pachana \& Dobson, 2010). Such unmeasured factors, which 273 are related to mortality and non-response, are likely leading to an informative sampling design in the new 274 Swiss census system, and may cause bias in survival analysis of survey data. In our analyses, we found 275 that IP weighting may adequately address the bias introduced by informative sampling. Our simulation 276 study confirmed that IP weights, using survival information from the full population, leads to comparable 277 MR estimates as those from known CS weights. The design of the present study - with a combination of 278 registry-based, survey and mortality information - allowed the identification of predictors, which are 279 associated with informative sampling, in a large population of 6.7 million individuals. This allowed us to 280 validate our findings for consistency. Because mortality information could be deterministically linked to a 281 registry and survey record - by using anonymous person identifiers - we could avoid uncertainty inherent 282 to probabilistic record linkages (Schmidlin et al., 2013). The Swiss Harmonized Registry Act Revision of the 283 year 2008 legally regulated the electronic exchange between communities and state personal registries, 284 and led to virtually no lost-to-follow-up of individuals.

285 Our present study has limitations. First, the IP weighting approaches is a design-based approach, i.e. the 286 probability distribution of participation in a random sample is treated as a fixed quantity (Hansen, 287 Madow \& Tepping, 1983; Little, 1983, 2004). Design-based approaches have been shown to be only 288 asymptotically unbiased, and potentially inefficient (Little, 2004; Kim \& Skinner, 2013). In the present 289 study we did not investigate model-based approaches, where non-participation in a random sample is 290 predicted using regression models (Gelman, 2007; Little, 2007). Further, IP modelling relies on strong 291 statistical assumptions which have to be fulfilled to provide unbiased statistical estimates (Scharfstein \& 292 Robins, 2002). In our setting, for example, exchangeability requires that the mortality among censored 293 and uncensored individuals is the same in participating and not-participating individuals, given all 294 predictors which predict mortality and those in the sampling design. However, researchers never know 295 whether all relevant predictors were identified and collected in a real data setting. Second, our approach 296 includes the outcome variable (i.e. survival status) in the IP weight construction. Thus, the validity of our 
297 estimates depends on the strength of the participation-outcome association and on the risk factor298 outcome association (i.e. age and gender) (Pizzi et al., 2011). Third, our findings are limited to observed 299 and available data within the registries and surveys. We could not investigate in more detail the real nonresponse patterns, i.e. which survey participants could not be contacted from the SFSO and whether sampled persons subsequently proved to have died were handled as non-responders or if they were excluded. Detailed information on those, who were contacted, but refused to participate, would strengthen our findings and could improve our estimates. Further, in the STATPOP population we could not differentiate whether individuals lived in a collective household (i.e. nursing homes) or not. This leads to a potential numerator/denominator bias, because the SE population is restricted to individuals living in a private household.

For many decades, most European countries relied on full enumeration censuses, where information for the whole population was collected at a specific reference date. A full enumeration census approach provides very detailed information on individual level (e.g. civil status, religion, household composition), but requires considerable financial and administrative resources. Registry-based and micro-census approaches are cost-efficient and require fewer resources. Among the countries of the United Nations Economic Commission for Europe (UNECE), there was an increase of registry-based and micro census approaches from $8 \%$ of all countries in 2000, to $19 \%$ in 2010 ("UNECE countries lead change in census methodology and technology, United Nations Economic Commission for Europe (UNECE), accessed (30 November 2017)"). However, from a statistical perspective they are prone to the sampling design errors, including informative sampling, and require adequate analysis techniques. In the following we give examples from other studies which analysed (or plan to analyse) mortality in samples of registry or census populations. One of the largest cohort studies worldwide - the Global Burden of Disease Study depends on a combination of complete and partially-complete (i.e. sampling information) registry and census information from different countries worldwide (Abajobir et al., 2017). To account for sampling and non-response errors, the study authors differentiate between different data sources and adjust for country-specific non-sampling error in their analysis. A study from the United Kingdom analysed mortality patterns from 1991-2011 from three different regions and data sources (Katikireddi et al., 2017). The analysis was based on information from the whole population of Northern Ireland, a 5.3\% sample of the Scottish population, and a 1\% sample of the English and Wales population. The authors calculated mortality rates stratified by sex, by estimating the number of expected deaths for the Scottish and English/Wales samples using a simulation approach. A recent study from Finland investigated

328 migrant mortality for the years 1939 to 2010 (Haukka et al., 2017). The authors used a 10\% sample of the 1950 and 1970 Finish population censuses, and calculated all-cause and cause-specific mortality rates. 
330 The authors discuss possible selection and attrition biases in their study limitations, but did not address

331 this kind of bias in sensitivity analyses. The German National Cohort (GNC) is a nationwide cohort study,

332 based on a sample of 200,000 German residents, which are recruited through a network of 18 study

333 centres (Ahrens et al., 2014). The authors estimated the anticipated response rate between 40 and $50 \%$,

334 but did not further specify how sampling bias will be included in their planned analyses. The above-

335 mentioned examples show that a combination of registry-based information and population-sampling

336 information play a crucial role in demographic and epidemiological research, and adequate analysis

337 strategies are necessary to avoid bias due to non-response and non-participation.

338 In the present study, we concluded that in Switzerland - which uses a combination of registry and survey-

339 based censuses - unweighted or CS weighted analyses lead to biased estimates, if the main outcome is

340 survival time. The observed bias from unweighted and CS weighted survival analysis is of importance for

341 absolute quantities (for example, mortality rates or life expectancy), but the bias may be less pronounced

342 in relative outcomes measures (for example, hazard ratios or odds ratios). We highlight that the IP

343 approach is not only restricted to the described setting of a change from a full enumeration census to a

344 micro census system, but may be generalized to other settings. For example, non-response in a full

345 enumeration census or lost-to-follow-up scenarios can be addressed by this approach to improve

346 longitudinal validity, given the non-response or non-participation is known in the study population. The

347 underrepresentation of population subgroups in survey data and possible selection bias have been

348 extensively discussed in the literature, but survey-based mortality analyses often lack validation using

349 registry data, or external data in general. Keiding and Louis exemplary discuss the limited generalisability

350 of survey data when external validation is lacking for internet-based surveys with possible self-selection

351 (Keiding \& Louis, 2016). Obviously, generalisability is more limited if the survey participation is

352 informative.

\section{Conclusion}

354 We conclude from our study that weighted regression analysis of census-linked survey data has to be 355 conducted carefully, and if possible, validated by registry-population information. If a validation or a 356 registry sampling weight construction is missing, estimation results have to be interpreted with caution 357 and might be biased.

\section{Acknowledgement}


359 We thank the Swiss Federal Statistical Office for providing mortality and census data and for the support 360 which made the Swiss National Cohort and this study possible. The members of the Swiss National 361 Cohort Study Group are Matthias Egger (Chairman of the Executive Board), Adrian Spoerri and Marcel 362 Zwahlen (all Bern), Milo Puhan (Chairman of the Scientific Board), Matthias Bopp (both Zurich), Nino 363 Künzli, Martin Röösli (both Basel), Murielle Bochud (Lausanne) and Michel Oris (Geneva). Further, we 364 thank Veronika Skrivankova for helpful comments in the preparation of the manuscript. 


\section{References}

Abajobir AA., Abate KH., Abbafati C., Abbas KM., Abd-Allah F., Abera SF., Abraha HN., Abu-Raddad LJ., Abu-Rmeileh NME., Adedeji IA., Adedoyin RA., Adetifa IMO., Adetokunboh O., Afshin A., Aggarwal R., Agrawal A., Agrawal S., Ahmad Kiadaliri A., Ahmed MB., Aichour MTE., Aichour AN., Aichour I., Aiyar S., Akanda AS., Akinyemiju TF., Akseer N., Al Lami FH., Alabed S., Alahdab F., Al-Aly Z., Alam K., Alam N., Alasfoor D., Aldridge RW., Alene KA., Al-Eyadhy A., Alhabib S., Ali R., Alizadeh-Navaei R., Aljunid SM., Alkaabi JM., Alkerwi A., Alla F., Allam SD., Allebeck P., Al-Raddadi R., Alsharif U., Altirkawi KA., Alvis-Guzman N., Amare AT., Ameh EA., Amini E., Ammar W., Amoako YA., Anber N., Andrei CL., Androudi S., Ansari H., Ansha MG., Antonio CAT., Anwari P., Ärnlöv J., Arora M., Artaman A., Aryal KK., Asayesh H., Asgedom SW., Asghar RJ., Assadi R., Assaye AM., Atey TM., Atre SR., AvilaBurgos L., Avokpaho EFGA., Awasthi A., Babalola TK., Bacha U., Badawi A., Balakrishnan K., Balalla S., Barac A., Barber RM., Barboza MA., Barker-Collo SL., Bärnighausen T., Barquera S., Barregard L., Barrero LH., Baune BT., Bazargan-Hejazi S., Bedi N., Beghi E., Béjot Y., Bekele BB., Bell ML., Bello AK., Bennett DA., Bennett JR., Bensenor IM., Benson J., Berhane A., Berhe DF., Bernabé E., Beuran M., Beyene AS., Bhala N., Bhansali A., Bhaumik S., Bhutta ZA., Bicer BK., Bidgoli HH., Bikbov B., Birungi C., Biryukov S., Bisanzio D., Bizuayehu HM., Bjerregaard P., Blosser CD., Boneya DJ., Boufous S., Bourne RRA., Brazinova A., Breitborde NJK., Brenner H., Brugha TS., Bukhman G., Bulto LNB., Bumgarner BR., Burch M., Butt ZA., Cahill LE., Cahuana-Hurtado L., Campos-Nonato IR., Car J., Car M., Cárdenas R., Carpenter DO., Carrero JJ., Carter A., Castañeda-Orjuela CA., Castro FF., Castro RE., Catalá-López F., Chen H., Chiang PPC., Chibalabala M., Chisumpa VH., Chitheer AA., Choi JYJ., Christensen H., Christopher DJ., Ciobanu LG., Cirillo M., Cohen AJ., Colquhoun SM., Coresh J., Criqui MH., Cromwell EA., Crump JA., Dandona L., Dandona R., Dargan PI., das Neves J., Davey G., Davitoiu D V., Davletov K., de Courten B., De Leo D., Degenhardt L., Deiparine S., Dellavalle RP., Deribe K., Deribew A., Des Jarlais DC., Dey S., Dharmaratne SD., Dherani MK., Diaz-Torné C., Ding EL., Dixit P., Djalalinia S., Do HP., Doku DT., Donnelly CA., dos Santos KPB., Douwes-Schultz D., Driscoll TR., Duan L., Dubey M., Duncan BB., Dwivedi LK., Ebrahimi H., El Bcheraoui C., Ellingsen CL., Enayati A., Endries AY., Ermakov SP., Eshetie S., Eshrati B., Eskandarieh S., Esteghamati A., Estep K., Fanuel FBB., Faro A., Farvid MS., Farzadfar F., Feigin VL., Fereshtehnejad SM., Fernandes JG., Fernandes JC., Feyissa TR., Filip I., Fischer F., Foigt N., Foreman KJ., Frank T., Franklin RC., Fraser M., Friedman J., Frostad JJ., Fullman N., Fürst T., Furtado JM., Futran ND., Gakidou E., Gambashidze K., Gamkrelidze A., Gankpé FG., Garcia-Basteiro AL., Gebregergs GB., Gebrehiwot TT., Gebrekidan KG., Gebremichael MW., Gelaye AA., Geleijnse JM., Gemechu BL., Gemechu KS., Genova-Maleras R., Gesesew HA., Gething PW., Gibney KB., Gill PS., Gillum RF., Giref AZ., Girma BW., Giussani G., Goenka S., Gomez B., Gona PN., Gopalani SV., Goulart AC., Graetz N., Gugnani HC., Gupta PC., Gupta R., Gupta R., Gupta T., Gupta V., Haagsma JA., Hafezi-Nejad N., Hakuzimana A., Halasa YA., Hamadeh RR., Hambisa MT., Hamidi S., Hammami M., Hancock J., Handal AJ., Hankey GJ., Hao Y., Harb HL., Hareri HA., Harikrishnan S., Haro JM., Hassanvand MS., Havmoeller R., Hay RJ., Hay SI., He F., Heredia-Pi IB., Herteliu C., Hilawe EH., Hoek HW., Horita N., Hosgood HD., Hostiuc S., Hotez PJ., Hoy DG., Hsairi M., Htet AS., Hu G., Huang J., Huang H., Iburg KM., Igumbor EU., Ileanu BV., Inoue M., Irenso AA., Irvine CMS., Islam SMS., Islam N., Jacobsen KH., Jaenisch T., Jahanmehr N., Jakovljevic MB., Javanbakht M., Jayatilleke AU., Jeemon P., Jensen PN., Jha V., Jin Y., John D., John O., Johnson SC., Jonas JB., Jürisson M., Kabir Z., Kadel R., Kahsay A., Kalkonde Y., Kamal R., Kan H., Karch A., Karema CK., Karimi SM., Karthikeyan G., Kasaeian A., Kassaw NA., Kassebaum NJ., Kastor A., Katikireddi SV., Kaul A., Kawakami N., Kazanjan K., Keiyoro PN., Kelbore SG., Kemp AH., Kengne AP., Keren A., Kereselidze M., Kesavachandran CN., Ketema EB., Khader YS., Khalil IA., Khan EA., Khan G., Khang YH., Khera S., Khoja ATA., Khosravi MH., Kibret GD., Kieling C., Kim YJ., Kim C il., Kim D., Kim P., Kim S., Kimokoti RW., Kinfu Y., Kishawi S., Kissoon N., Kivimaki M., Knudsen AK., Kokubo Y., Kopec JA., Kosen S., Koul PA., Koyanagi A., Kravchenko M., Krohn KJ., Kuate Defo B., Kuipers EJ., Kulikoff XR., Kulkarni VS., Kumar GA., Kumar P., Kumsa FA., Kutz M., Lachat C., Lagat AK., Lager ACJ., Lal DK., Lalloo R., Lambert 
414

415

416

417

418

419

420

421

422

423

424

425

426

427

428

429

430

431

432

433

434

435

436

437

438

439

440

441

442

443

444
N., Lan Q., Lansingh VC., Larson HJ., Larsson A., Laryea DO., Lavados PM., Laxmaiah A., Lee PH., Leigh J., Leung J., Leung R., Levi M., Li Y., Liao Y., Liben ML., Lim SS., Linn S., Lipshultz SE., Liu S., Lodha R., Logroscino G., Lopez AD., Lorch SA., Lorkowski S., Lotufo PA., Lozano R., Lunevicius R., Lyons RA., Ma S., Macarayan ERK., Machado IE., Mackay MT., Magdy Abd El Razek M., MagisRodriguez C., Mahdavi M., Majdan M., Majdzadeh R., Majeed A., Malekzadeh R., Malhotra R., Malta DC., Mantovani LG., Manyazewal T., Mapoma CC., Marczak LB., Marks GB., Martin EA., MartinezRaga J., Martins-Melo FR., Massano J., Maulik PK., Mayosi BM., Mazidi M., McAlinden C., McGarvey ST., McGrath JJ., McKee M., Mehata S., Mehndiratta MM., Mehta KM., Meier T., Mekonnen TC., Meles KG., Memiah P., Memish ZA., Mendoza W., Mengesha MM., Mengistie MA., Mengistu DT., Menon GR., Menota BG., Mensah GA., Meretoja TJ., Meretoja A., Mezgebe HB., Micha R., Mikesell J., Miller TR., Mills EJ., Minnig S., Mirarefin M., Mirrakhimov EM., Misganaw A., Mishra SR., Mohammad KA., Mohammadi A., Mohammed KE., Mohammed S., Mohan MBV., Mohanty SK., Mokdad AH., Mollenkopf SK., Molokhia M., Monasta L., Montañez Hernandez JC., Montico M., Mooney MD., Moore AR., Moradi-Lakeh M., Moraga P., Morawska L., Mori R., Morrison SD., Mruts KB., Mueller UO., Mullany E., Muller K., Murray CJL., Murthy GVS., Murthy S., Musa KI., Nachega JB., Nagata C., Nagel G., Naghavi M., Naidoo KS., Nanda L., Nangia V., Nascimento BR., Natarajan G., Negoi I., Nguyen CT., Nguyen Q Le., Nguyen TH., Nguyen G., Ningrum DNA., Nisar MI., Nomura M., Nong VM., Norheim OF., Norrving B., Noubiap JJN., Nyakarahuka L., O'Donnell MJ., Obermeyer CM., Ogbo FA., Oh IH., Okoro A., Oladimeji O., Olagunju AT., Olusanya BO., Olusanya JO., Oren E., Ortiz A., Osgood-Zimmerman A., Ota E., Owolabi MO., Oyekale AS., PA M., Pacella RE., Pakhale S., Pana A., Panda BK., Panda-Jonas S., Park EK., Parsaeian M., Patel T., Patten SB., Patton GC., Paudel D., Pereira DM., Perez-Padilla R., Perez-Ruiz F., Perico N., Pervaiz A., Pesudovs K., Peterson CB., Petri WA., Petzold M., Phillips MR., Piel FB., Pigott DM., Pishgar F., Plass D., Polinder S., Popova S., Postma MJ., Poulton RG., Pourmalek F., Prasad N., Purwar M., Qorbani M., Quintanilla BPA., Rabiee RHS., Radfar A., Rafay A., Rahimi-Movaghar A., Rahimi-Movaghar V., Rahman MHU., Rahman SU., Rahman M., Rai RK., Rajsic S., Ram U., Rana SM., Ranabhat CL., Rao PV., Rawaf S., Ray SE., Rego MAS., Rehm J., Reiner RC., Remuzzi G., Renzaho AMN., Resnikoff S., Rezaei S., Rezai MS., Ribeiro AL., Rivas JC., Rokni MB., Ronfani L., Roshandel G., Roth GA., Rothenbacher D., Roy A., Rubagotti E., Ruhago GM., Saadat S., Sabde YD., Sachdev PS., Sadat N., Safdarian M., Safi S., Safiri S., Sagar R., Sahathevan R., Sahebkar A., Sahraian MA., Salama J., Salamati P., Salomon JA., Salvi SS., Samy AM., Sanabria JR., SanchezNiño MD., Santos IS., Santric Milicevic MM., Sarmiento-Suarez R., Sartorius B., Satpathy M., Sawhney M., Saxena S., Saylan MI., Schmidt MI., Schneider IJC., Schulhofer-Wohl S., Schutte AE., Schwebel DC., Schwendicke F., Seedat S., Seid AM., Sepanlou SG., Servan-Mori EE., Shackelford KA., Shaheen A., Shahraz S., Shaikh MA., Shamsipour M., Shamsizadeh M., Sharma J., Sharma R., She J., Shen J., Shetty BP., Shi P., Shibuya K., Shifa GT., Shigematsu M., Shiri R., Shiue I., Shrime MG., Sigfusdottir ID., Silberberg DH., Silpakit N., Silva DAS., Silva JP., Silveira DGA., Sindi S., Singh JA., Singh PK., Singh A., Singh V., Sinha DN., Skarbek KAK., Skiadaresi E., Sligar A., Smith DL., Sobaih BHA., Sobngwi E., Soneji S., Soriano JB., Sreeramareddy CT., Srinivasan V., Stathopoulou V., Steel N., Stein DJ., Steiner C., Stöckl H., Stokes MA., Strong M., Sufiyan MB., Suliankatchi RA., Sunguya BF., Sur PJ., Swaminathan S., Sykes BL., Szoeke CEI., Tabarés-Seisdedos R., Tadakamadla SK., Tadese F., Tandon N., Tanne D., Tarajia M., Tavakkoli M., Taveira N., Tehrani-Banihashemi A., Tekelab T., Tekle DY., Temsah MH., Terkawi AS., Tesema CL., Tesssema B., Theis A., Thomas N., Thompson AH., Thomson AJ., Thrift AG., Tiruye TY., Tobe-Gai R., Tonelli M., Topor-Madry R., Topouzis F., Tortajada M., Tran BX., Truelsen T., Trujillo U., Tsilimparis N., Tuem KB., Tuzcu EM., Tyrovolas S., Ukwaja KN., Undurraga EA., Uthman OA., Uzochukwu BSC., van Boven JFM., Varakin YY., Varughese S., Vasankari T., Vasconcelos AMN., Velasquez IM., Venketasubramanian N., Vidavalur R., Violante FS., Vishnu A., Vladimirov SK., Vlassov VV., Vollset SE., Vos T., Waid JL., Wakayo T., Wang H., Wang YP., Weichenthal S., Weiderpass E., Weintraub RG., Werdecker A., Wesana J., Wijeratne T., Wilkinson JD., Wiysonge CS., Woldeyes BG., Wolfe CDA., Workicho A., Workie SB., Xavier D., Xu G., Yaghoubi M., Yakob B., Yalew AZ., Yan LL., Yano Y., Yaseri M., Ye P., Yimam HH., Yip P., Yirsaw BD., Yonemoto N., Yoon SJ., 
464

465

466

467

468

469

470

471

472

473

474

475

476

477

478

479

480

481

482

Yotebieng M., Younis MZ., Zaidi Z., Zaki MES., Zeeb H., Zenebe ZM., Zerfu TA., Zhang AL., Zhang X., Zodpey S., Zuhlke LJ. 2017. Global, regional, and national under-5 mortality, adult mortality, agespecific mortality, and life expectancy, 1970-2016: a systematic analysis for the Global Burden of Disease Study 2016. The Lancet 390:1084-1150. DOI: 10.1016/S0140-6736(17)31833-0.

Ahrens W., Hoffmann W., Jöckel KH., Kaaks R., Gromer B., Greiser KH., Linseisen J., Schmidt B., Wichmann HE., Weg-Remers S. 2014. The German National Cohort: Aims, study des. European Journal of Epidemiology 29:371-382. DOI: 10.1007/s10654-014-9890-7.

Assoulin D. 2012. Methodische Grundlage zu den ersten Hochrechnungsresultaten der Strukturerhebung 2010 vom 19. Juni 2012. Swiss Federal Statistical Office, Neuchâtel.

Barchielli A., Balzi D. 2002. Nine-year follow-up of a survey on smoking habits in Florence (Italy): higher mortality among non-responders. International journal of epidemiology 31:1038-1042. DOI: 10.1093/ije/31.5.1038.

Bopp M., Braun J., Faeh D. 2014. Variation in mortality patterns among the general population, study participants, and different types of nonparticipants: Evidence from 25 years of follow-up. American Journal of Epidemiology 180:1028-1035. DOI: 10.1093/aje/kwu226.

Bopp M., Spörri A., Zwahlen M., Gutzwiller F., Paccaud F., Braun-Fahrländer C., Rougemont A., Egger M. 2009. Cohort Profile: the Swiss National Cohort--a longitudinal study of 6.8 million people. International journal of epidemiology 38:379-384.

Boudreau C., Lawless J. 2006. Survival analysis based on the proportional hazards model and survey data. The Canadian Journal of Statistics 34:203-216. DOI: 10.1002/cjs.5550340202.

Brilleman SL., Pachana NA., Dobson AJ. 2010. The impact of attrition on the representativeness of cohort studies of older people. BMC Medical Research Methodology 10:71. DOI: 10.1186/1471-2288-1071.

Connelly R., Platt L. 2014. Cohort Profile: UK Millennium Cohort Study (MCS). International Journal of Epidemiology 43:1719-1725. DOI: 10.1093/ije/dyu001.

Fuller WA. 2009. Sampling Statistics. New York: Wiley.

Gelman A. 2007. Struggles with Survey Weighting and Regression Modeling. Statistical Science 22:153164. DOI: $10.1214 / 088342306000000691$.

Hansen MH., Madow WG., Tepping BJ. 1983. An evaluation of model-dependent and probabilitysampling inferences in sample surveys. Journal of the American Statistical Association 78:776-793. DOI: $10.2307 / 2288182$.

Haukka J., Suvisaari J., Sarvimäki M., Martikainen P. 2017. The Impact of Forced Migration on Mortality. Epidemiology 28:587-593. DOI: 10.1097/EDE.0000000000000669.

Katikireddi SV., Leyland AH., McKee M., Ralston K., Stuckler D. 2017. Patterns of mortality by occupation in the UK, 1991-2011: A comparative analysis of linked census and mortality records. The Lancet Public Health:501-512. DOI: 10.1016/S2468-2667(17)30193-7.

Keiding N., Louis TA. 2016. Perils and potentials of self-selected entry to epidemiological studies and surveys. Journal of the Royal Statistical Society. Series A: Statistics in Society 179:319-376. DOI: 10.1111/rssa.12136.

Kim JK., Skinner CJ. 2013. Weighting in survey analysis under informative sampling. Biometrika 100:385398. DOI: 10.1093/biomet/ass085. 


\section{Manuscript to be reviewed}

505

506

507

508

509

510

511

512

513

514

515

516

517

518

519

520

521

522

523

524

525

526

527

528

529

530

531

532

533

534

535

536

Korn EL., Graubard BI. 1999. Analysis of Health Surveys. New York: Wiley.

Lawless J. 2003. Censoring and weighting in survival estimation from survey data. In: SSC Annual Meeting, Proceedings of the Survey Methods Section. 31-36.

Little RJ. 1983. An evaluation of model-dependent and probability-sampling inferences in sample surveys: Comment. Journal of the American Statistical Association 78:797-799. DOI: 10.2307/2288182.

Little RJ. 2004. To Model or Not To Model? Competing Modes of Inference for Finite Population Sampling. Journal of the American Statistical Association 99:546-556. DOI: 10.1198/016214504000000467.

Little RJ. 2007. Comment: Struggles with Survey Weighting and Regression Modeling. Statistical Science 22:171-174. DOI: 10.1214/088342306000000691.

Moser A., Clough-Gorr K., Zwahlen M. 2015. Modeling absolute differences in life expectancy with a censored skew-normal regression approach. PeerJ 3:e1162. DOI: 10.7717/peerj.1162.

Moser A., Panczak R., Zwahlen M., Clough K., Spörri A., Stuck A., Egger M. 2014. What does your neighbourhood say about you? A study of life expectancy in 1.3 million Swiss neighbourhoods. Journal of epidemiology and community health 68:1125-1132. DOI: 10.1136/jech-2014-204352.

Nielsen MB., Knardahl S. 2016. The healthy worker effect: Do health problems predict participation rates in, and the results of, a follow-up survey? International Archives of Occupational and Environmental Health 89:231-238. DOI: 10.1007/s00420-015-1066-6.

Olsen J., Melbye M., Olsen SF., Sorensen TIA., Aaby P., Nybo Andersen A-M., Taxbol D., Hansen KD., Juhl M., Schow TB., Sorensen HT., Andresen J., Mortensen EL., Wind Olesen A., Sondergaard C. 2001. The Danish National Birth Cohort - its background, structure and aim. Scandinavian Journal of Public Health 29:300-307. DOI: 10.1177/14034948010290040201.

Pfeffermann D. 2010. Modelling of complex survey data: Why model? Why is it a problem? How can we approach it? Survey Methodology:1-23.

Pizzi C., De Stavola B., Merletti F., Bellocco R., dos Santos Silva I., Pearce N., Richiardi L. 2011. Sample selection and validity of exposure-disease association estimates in cohort studies. Journal of epidemiology and community health 65:407-411. DOI: 10.1136/jech.2009.107185.

Pizzi C., De Stavola BL., Pearce N., Lazzarato F., Ghiotti P., Merletti F., Richiardi L. 2012. Selection bias and patterns of confounding in cohort studies: the case of the NINFEA web-based birth cohort. Journal of Epidemiology \& Community Health 66:976-981. DOI: 10.1136/jech-2011-200065.

Pyy-Martikainen M. 2013. Approaches for event history analysis based on complex longitudinal survey data. AStA Advances in Statistical Analysis 97:297-315. DOI: 10.1007/s10182-012-0205-6.

Qualité L., Statistik B., Europe E De. 2014. Auswahl und Gewichtung der Stichprobe der schweizerischen Strukturerhebung. Swiss Federal Statistical Office, Neuchâtel.

Renaud A. 2004. Coverage Estimation for the Swiss Population Census 2000. Swiss Federal Statistical Office, Neuchâtel.

Rochat S., Kauthen J., Eichenberger P. 2009. Strukturerhebung: Aufstockungsmodelle für die Kantone. Swiss Federal Statistical Office, Neuchâtel.

Scharfstein DO., Robins JM. 2002. Estimation of the failure time distribution in the presence of informative censoring. Biometrika 89:617-634. DOI: 10.1093/biomet/89.3.617.

Schmidlin K., Clough-Gorr KM., Spoerri A., Egger M., Zwahlen M. 2013. Impact of unlinked deaths and 
545 coding changes on mortality estimates in the Swiss National Cohort. BMC Medical Informatics and 546 Desicion Making 13:1. DOI: 10.1186/1472-6947-13-1.

547 Spoerri A., Zwahlen M., Egger M., Bopp M. 2010. The Swiss National Cohort: A unique database for 548 national and international researchers. International Journal of Public Health 55:239-242. DOI:

$549 \quad 10.1007 / \mathrm{s} 00038-010-0160-5$.

550 UNECE countries lead change in census methodology and technology, United Nations Economic Commission for Europe (UNECE), accessed (30 November 2017). Available at https://www.unece.org/info/media/news/statistics/2016/unece-countries-lead-change-in-censusmethodology-and-technology/doc.html

White IR., Royston P. 2009. Imputing missing covariate values for the Cox model. Statistics in Medicine 28:1982-1998. DOI: 10.1002/sim.3618. 


\section{Table $\mathbf{1}$ (on next page)}

Description of registry-based population (STATPOP) and the micro census (structural enquiry, SE) 2010, by survival status*.

* Follow-up period defined from December 31, 2010 to December 31, 2011. 
Structural enquiry sample

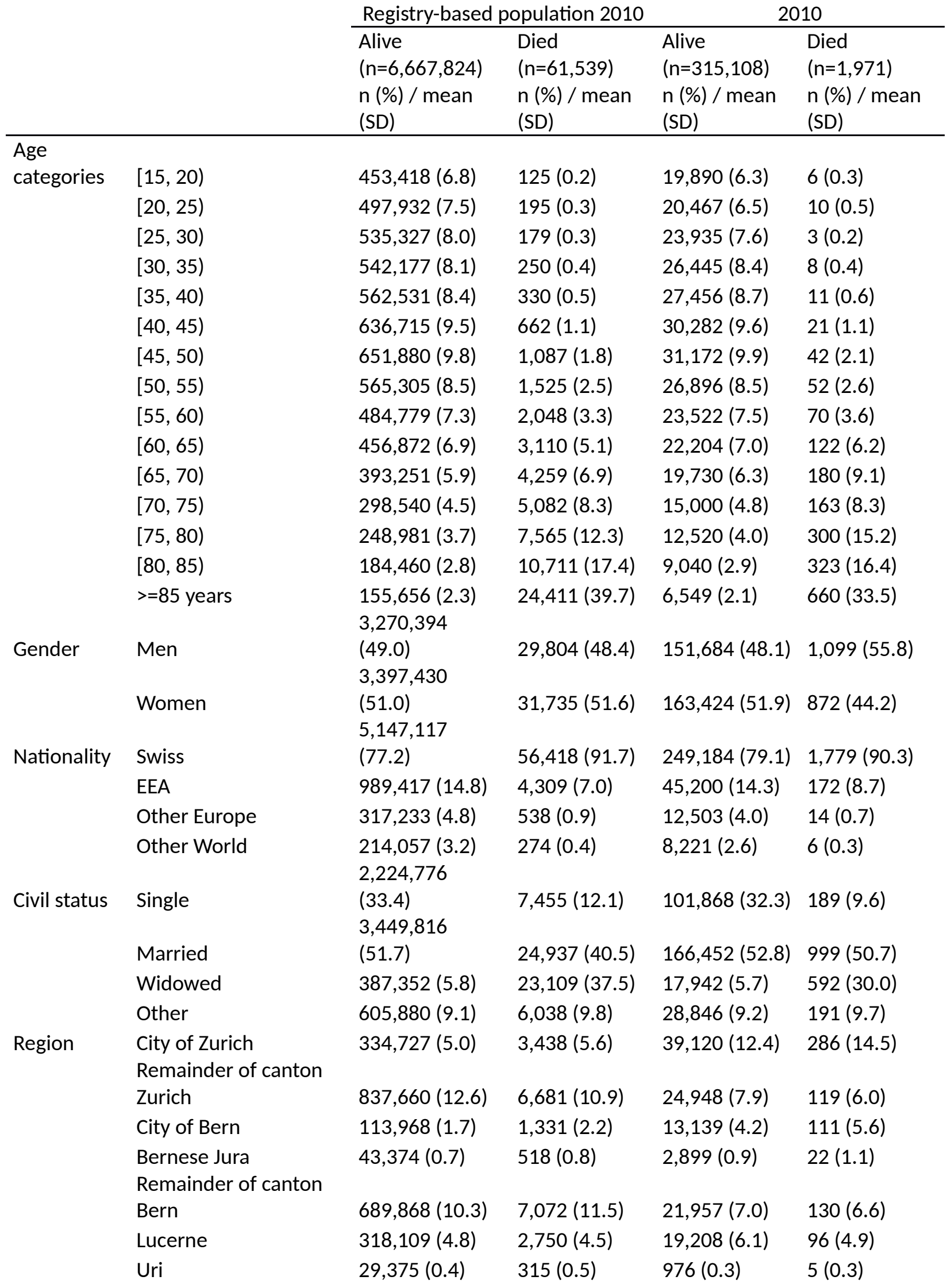




\begin{tabular}{lllll} 
Schwyz & $122,585(1.8)$ & $1,053(1.7)$ & $3,589(1.1)$ & $19(1.0)$ \\
Obwalden & $29,675(0.4)$ & $249(0.4)$ & $828(0.3)$ & $4(0.2)$ \\
Nidwalden & $34,471(0.5)$ & $270(0.4)$ & $1,039(0.3)$ & $6(0.3)$ \\
Glarus & $32,785(0.5)$ & $364(0.6)$ & $914(0.3)$ & $7(0.4)$ \\
Zug & $94,883(1.4)$ & $704(1.1)$ & $5,205(1.7)$ & $23(1.2)$ \\
Fribourg & $228,838(3.4)$ & $1,948(3.2)$ & $6,570(2.1)$ & $39(2.0)$ \\
Solothurn & $216,854(3.3)$ & $2,161(3.5)$ & $6,598(2.1)$ & $54(2.7)$ \\
Basel-Stadt & $162,021(2.4)$ & $2,026(3.3)$ & $5,113(1.6)$ & $26(1.3)$ \\
Basel-Landschaft & $234,029(3.5)$ & $2,195(3.6)$ & $7,366(2.3)$ & $44(2.2)$ \\
Schaffhausen & $65,688(1.0)$ & $713(1.2)$ & $2,001(0.6)$ & $18(0.9)$ \\
Appenzell & & & & \\
Ausserrhoden & $43,940(0.7)$ & $444(0.7)$ & $1,382(0.4)$ & $15(0.8)$ \\
Appenzell Innerrhoden & $12,738(0.2)$ & $135(0.2)$ & $381(0.1)$ & $2(0.1)$ \\
St. Gallen & $405,528(6.1)$ & $3,657(5.9)$ & $12,174(3.9)$ & $57(2.9)$ \\
Graubuenden & $174,072(2.6)$ & $1,615(2.6)$ & $5,070(1.6)$ & $32(1.6)$ \\
Aargau & $513,802(7.7)$ & $4,350(7.1)$ & $30,046(9.5)$ & $164(8.3)$ \\
Thurgau & $209,311(3.1)$ & $1,881(3.1)$ & $12,137(3.9)$ & $73(3.7)$ \\
Ticino & $284,417(4.3)$ & $2,856(4.6)$ & $17,343(5.5)$ & $123(6.2)$ \\
Vaud & $603,119(9.0)$ & $5,165(8.4)$ & $34,465(10.9)$ & $232(11.8)$ \\
Valais & $265,481(4.0)$ & $2,492(4.0)$ & $7,112(2.3)$ & $49(2.5)$ \\
Neuchâtel & $143,272(2.1)$ & $1,501(2.4)$ & $9,295(2.9)$ & $73(3.7)$ \\
Geneva & $365,634(5.5)$ & $3,013(4.9)$ & $20,510(6.5)$ & $112(5.7)$ \\
Jura & $57,600(0.9)$ & $642(1.0)$ & $3,723(1.2)$ & $30(1.5)$ \\
\hline & & & &
\end{tabular}




\section{Table 2 (on next page)}

Crude odds ratios (OR) of participation in the 2010 micro census, with the registrybased population 2010 as reference population. 


\begin{tabular}{|c|c|c|}
\hline \multirow[t]{15}{*}{ Age categories } & {$[15,20)$} & Reference \\
\hline & {$[20,25)$} & $0.93(0.92,0.95)$ \\
\hline & {$[25,30)$} & $1.02(1.00,1.04)$ \\
\hline & {$[30,35)$} & $1.12(1.10,1.14)$ \\
\hline & {$[35,40)$} & $1.12(1.10,1.14)$ \\
\hline & {$[40,45)$} & $1.09(1.07,1.11)$ \\
\hline & {$[45,50)$} & $1.09(1.07,1.11)$ \\
\hline & {$[50,55)$} & $1.09(1.07,1.11)$ \\
\hline & {$[55,60)$} & $1.11(1.09,1.13)$ \\
\hline & {$[60,65)$} & $1.11(1.09,1.13)$ \\
\hline & {$[65,70)$} & $1.15(1.13,1.17)$ \\
\hline & {$[70,75)$} & $1.15(1.12,1.17)$ \\
\hline & {$[75,80)$} & $1.15(1.12,1.17)$ \\
\hline & {$[80,85)$} & $1.10(1.07,1.13)$ \\
\hline & >=85 years & $0.91(0.88,0.93)$ \\
\hline \multirow[t]{2}{*}{ Gender } & Men & Reference \\
\hline & Women & $1.04(1.03,1.04)$ \\
\hline \multirow[t]{4}{*}{ Nationality } & Swiss & Reference \\
\hline & EEA & $0.94(0.93,0.95)$ \\
\hline & Other Europe & $0.81(0.79,0.82)$ \\
\hline & Other World & $0.79(0.77,0.81)$ \\
\hline \multirow[t]{4}{*}{ Civil status } & Single & Reference \\
\hline & Married & $1.06(1.05,1.07)$ \\
\hline & Widowed & $0.99(0.97,1.00)$ \\
\hline & Other & $1.04(1.03,1.05)$ \\
\hline \multirow[t]{23}{*}{ Region } & City of Zurich & $4.31(4.24,4.38)$ \\
\hline & Remainder of canton & \\
\hline & Zurich & Reference \\
\hline & City of Bern & $4.24(4.15,4.34)$ \\
\hline & Bernese Jura & $2.33(2.24,2.42)$ \\
\hline & Remainder of canton Bern & $1.07(1.05,1.09)$ \\
\hline & Lucerne & $2.09(2.05,2.13)$ \\
\hline & Uri & $1.12(1.05,1.19)$ \\
\hline & Schwyz & $0.98(0.95,1.02)$ \\
\hline & Obwalden & $0.93(0.87,1.00)$ \\
\hline & Nidwalden & $1.01(0.95,1.08)$ \\
\hline & Glarus & $0.93(0.87,1.00)$ \\
\hline & Zug & $1.89(1.83,1.95)$ \\
\hline & Fribourg & $0.96(0.94,0.99)$ \\
\hline & Solothurn & $1.02(1.00,1.05)$ \\
\hline & Basel-Stadt & $1.06(1.03,1.09)$ \\
\hline & Basel-Landschaft & $1.06(1.03,1.09)$ \\
\hline & Schaffhausen & $1.02(0.98,1.07)$ \\
\hline & Appenzell Ausserrhoden & $1.06(1.01,1.12)$ \\
\hline & Appenzell Innerrhoden & $1.00(0.90,1.11)$ \\
\hline & St. Gallen & $1.01(0.99,1.03)$ \\
\hline & Graubuenden & $0.98(0.95,1.01)$ \\
\hline & Aargau & $2.02(1.99,2.06)$ \\
\hline
\end{tabular}




\begin{tabular}{lll} 
& Thurgau & $2.01(1.96,2.05)$ \\
Ticino & $2.12(2.07,2.16)$ \\
Vaud & $1.98(1.94,2.01)$ \\
Valais & $0.90(0.87,0.92)$ \\
& Neuchâtel & $2.26(2.21,2.32)$ \\
& Geneva & $1.94(1.90,1.97)$ \\
& Jura & $2.25(2.17,2.33)$ \\
Vital status by end of year & Alive & Reference \\
& Death & $0.67(0.64,0.70)$ \\
\hline
\end{tabular}




\section{Figure 1 (on next page)}

Directed acyclic graph for informative sampling situation*.

* An unmeasured predictor, say poor health status, is directly related to survival. Older men (observed predictors age and gender) are assumed to have more likely a poor health status. Further, individuals with a poor health status are less likely to respond to a survey questionnaire (nonresponse). Nonresponse has a direct effect on the effective sample. Conditioning on the effective sample (collider, indicated by box) opens the path "Random sample -> Nonresponse -> Unmeasured predictor -> Survival", and introduces a spurious association between the sampling selection and survival. 


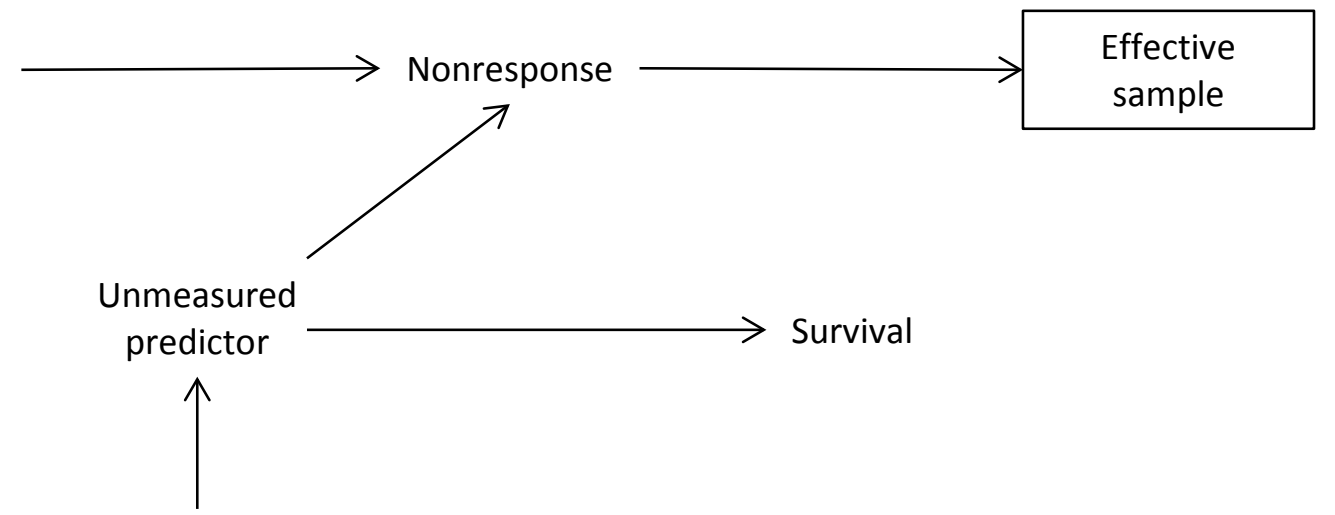

Age, gender 


\section{Figure 2 (on next page)}

Population and weighted mortality rates from December 31, 2010 to December 31, 2011, by gender*.
(A) Men. (B) Women.

Abbreviations: CSW Calibrated survey weights; IPW Inverse probability weights; SE Structural enquiry; STATPOP Registry-based population.

* Permanent residents living in Switzerland aged 15 years or older at December 31, 2010. Y-axis is on a logarithmic scale. 


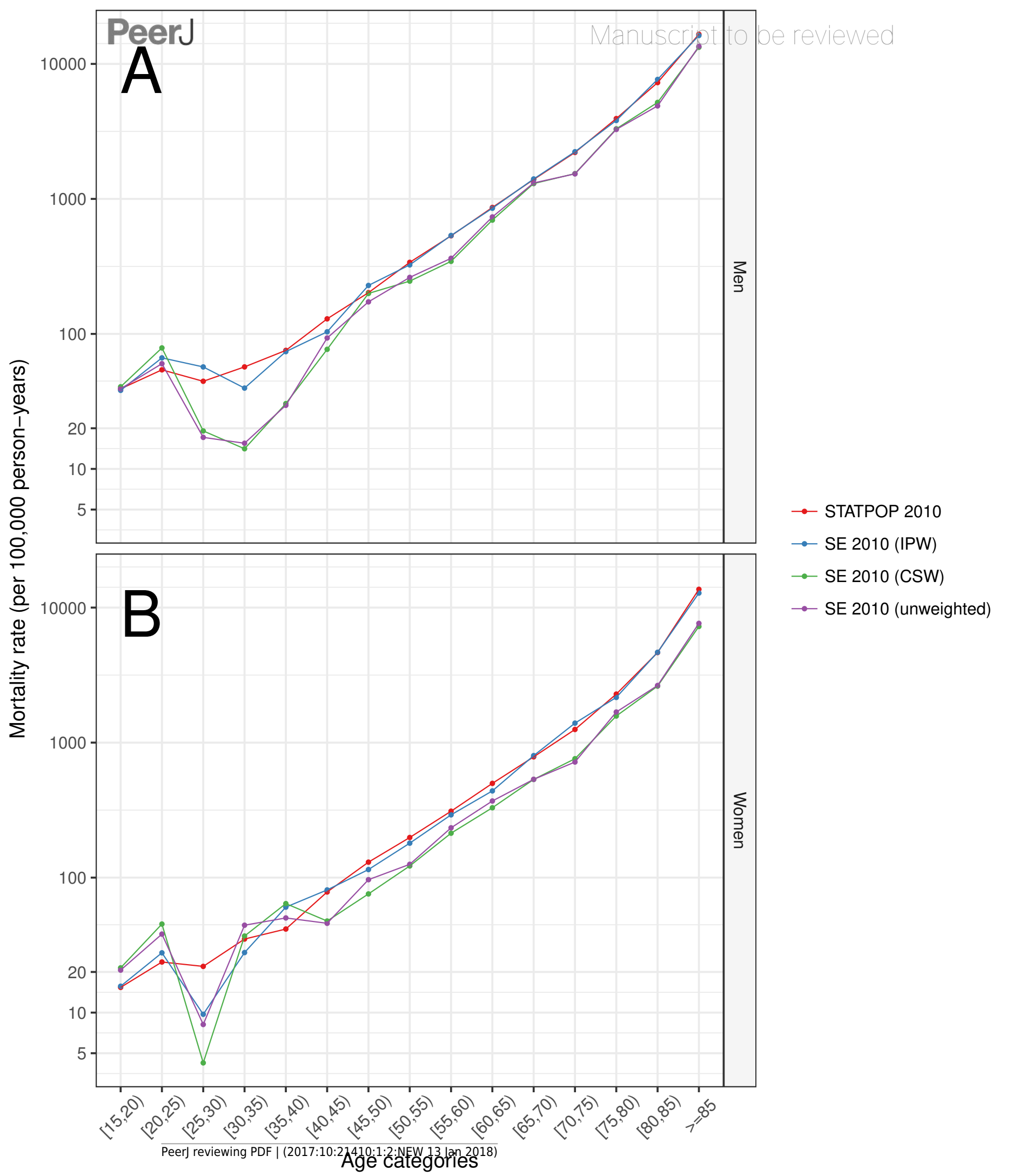




\section{Figure 3 (on next page)}

Life expectancy at age 30 years, by gender.

(A) Men. (B) Women.

Abbreviations: CSW Calibrated survey weights; IPW Inverse probability weights; SE Structural enquiry; STATPOP Registry-based population. 
